This item was submitted to Loughborough's Research Repository by the author.

Items in Figshare are protected by copyright, with all rights reserved, unless otherwise indicated.

\title{
Predicting the safety impact of a speed limit increase using condition-based multivariate Poisson lognormal regression
}

\section{PLEASE CITE THE PUBLISHED VERSION}

http://dx.doi.org/10.1080/03081060.2015.1108080

\section{PUBLISHER}

(c) Taylor \& Francis

\section{VERSION}

AM (Accepted Manuscript)

\section{PUBLISHER STATEMENT}

This work is made available according to the conditions of the Creative Commons Attribution-NonCommercialNoDerivatives 4.0 International (CC BY-NC-ND 4.0) licence. Full details of this licence are available at: https://creativecommons.org/licenses/by-nc-nd/4.0/

\section{LICENCE}

CC BY-NC-ND 4.0

\section{REPOSITORY RECORD}

Imprialou, Marianna, Mohammed A. Quddus, and D.E. Pitfield. 2019. "Predicting the Safety Impact of a Speed Limit Increase Using Condition-based Multivariate Poisson Lognormal Regression”. figshare.

https://hdl.handle.net/2134/19642. 
1 Predicting the safety impact of a speed limit increase using condition-

2 based multivariate Poisson lognormal regression

3 Maria-Ioanna M. Imprialou*, Mohammed Quddus, David E. Pitfield

4 School of Civil and Building Engineering, Loughborough University, Loughborough,

$5 \quad$ United Kingdom

6 School of Civil and Building Engineering, Loughborough University, Loughborough

7 LE11 3TU, United Kingdom,Tel: +44(0)1509 228545, email: M.Imprialou@lboro.ac.uk

8

9

10

11

12

13

14

15

16

17

18

19

20

21

22

*corresponding author

23 


\section{Predicting the safety impact of a speed limit increase using condition-}

\section{2 based Multivariate Poisson lognormal regression}

Speed limit changes are considered to lead to proportional changes in the number and severity of crashes. To predict the impact of a speed limit alteration, it is necessary to define a relationship between crashes and speed on a road network. This paper examines the relationship of crashes with speed, as well as with other traffic and geometric variables, on the UK motorways in order to estimate the impact of a potential speed limit increase from $70 \mathrm{mph}$ to $80 \mathrm{mph}$ on traffic safety. Full Bayesian multivariate Poisson lognormal regression models are applied to a dataset aggregated using the condition-based approach for crashes by vehicle (i.e. single-vehicle and multiple-vehicle) and severity (i.e. fatal or serious and slight). The results show that single-vehicle crashes of all severities and fatal or serious injury crashes involving multiple vehicles increase at higher speed conditions and particularly when these are combined with lower volumes. Slight injury multiple-vehicle crashes are found not to be related with high speeds, but instead with congested traffic. Using the speed elasticity values derived from the models the predicted annual increase in crashes after a speed limit increase on the UK motorway is found to be $6.2-12.1 \%$ for fatal or serious injury crashes and $1.3-2.7 \%$ for slight injury, or else up to 167 more crashes.

Keywords: speed limit increase; speed and crashes; single vehicle crashes; multiple vehicle crashes; condition-based modelling

\section{Introduction}

The aim of speed limits is to maintain the equilibrium between road safety, traffic flow and energy consumption in road networks (TRB 1998; Department for Transport 2006). Although speed limits should not be considered as the target speed, a great proportion of drivers in Great Britain systematically exceed the speed limits; in 2013 47\% of cars violated the $70 \mathrm{mph}$ speed limit, leading to an annual $85^{\text {th }}$ percentile of speed as high as 77mph (Department for Transport 2014). One could argue that these figures indicate that the current speed limit needs to be updated, as it was formerly proposed by the Department for Transport in 2011 (Department for Transport 2011a). On the other hand, 
1 a speed limit increase raises concerns about its potential safety consequences. To assess

2 whether a speed limit increase is sensible and appropriate it is necessary to estimate its

3 future impact on road safety.

4

The relationship of speed with crashes is the key to the quantification of the impact of speed limit changes. The majority of the before-after studies report that speed limit alterations lead to proportional changes in crash frequency (Elvik, Christensen, and Amundsen 2004; Aarts and Van Schagen 2006). This effect is always attributed to the increase of average speeds on the roadway; however, when the relationship of speed with crashes is examined individually the outcomes remain rather inconclusive. The literature includes studies that have found a proportional (e.g. Kloeden, McLean, and Glonek 2002), inversely proportional (e.g. Baruya 1998a) and insignificant (e.g. Kockelman and Ma 2007) relationships between speed and crashes. The inconsistency in the results may lie in the inability of the link-based crash aggregation approaches to represent the actual conditions on the network and also the tendency to examine highly aggregated crash counts as a basis for the analysis. Link-based analyses use variables that are by default highly aggregated as they represent an entire link with one characteristic value (e.g. time-varying measures are usually represented by annual averages) (Clark and Avery 1976). In this way it is likely that the spatial and temporal variations within the link are not captured, making the representation of the pre-crash conditions practically impossible. Moreover, analysing all crash types combined may reduce the capability of models to reveal the actual crash contributory factors as those are found to vary between different crash generation processes (Geedipally and Lord 2010; D. G. Kim et al. 2007). The aim of this paper is to explore the relationship between speed and vehicle crashes on the UK motorways in order to quantify the safety impact of a potential speed 
1 limit increase from $70 \mathrm{mph}$ to $80 \mathrm{mph}$ on the UK motorways. The study is based on the

2 development of advanced statistical models that address some of the limitations of the

3 link-based models and therefore lead to more accurate predictions on the changes on

4 crash frequency that can be expected after a speed limit increase. This paper is organised as follows: firstly, the key empirical findings and the

6 current methodological approaches of the existing literature are reviewed. Next, is the

7 presentation of the data used for the analysis as well as their pre-processing method.

8 This is followed by the description of the statistical method and the results on the effect

9 of a speed increase on crashes by type. The final section summarises the main outcomes

10 of the study and some recommendations for future research.

\section{Literature Review}

12 Speed limit changes lead to proportional but comparatively moderate changes in the

13 average speed of road networks (Rock 1995). Literature suggests that the average speed

14 change equals approximately to one quarter to half of the speed limit difference (e.g.

15 Aljanahi, Rhodes, and Metcalfe 1999; Baruya 1998b; Elvik, Christensen, and

16 Amundsen 2004; Finch et al. 1994; Freedman and Williams 1992). Assuming that a

17 relationship between speed and crash frequency exists, a speed limit increase, if all

18 other factors remain unchanged, should lead to increased number of crashes on a road

19 network. This is confirmed by most (70.5\%, weighted percentage) of the before-after

20 studies that examined the impact of speed raises and were included in a meta-analysis

21 by Elvik et al. (2004) .

22 There have been several attempts in the literature to define a general rule for the

23 impact of speed limit changes; most of them are based on the combination of the

24 outcomes of previous studies (i.e. meta-analyses). Nilsson (2004) suggested that the 
1 impact of a speed limit change can be quantified using a Power model that was

2 validated in two extensive meta-analyses by Elvik et al. ( 2004) and Elvik ( 2009) where

3 they developed several power functions suitable for impact estimation. The use of

4 power functions is a straightforward and transferrable method however its main

5 drawback is that the exponents provided are independent of the baseline speed that

6 might not lead to accurate estimations. This was initially suggested by Hauer and

7 Bonnenson (Hauer and Bonneson 2006) who addressed some of the Power Model's

8 limitations developing an exponential model using data from Elvik’s et al. meta-

9 analysis ((Elvik, Christensen, and Amundsen 2004).

10 Meta-analyses' results are useful for identifying general data patterns, but may

11 be not accurate enough for predicting the effect of a speed limit increase in a particular

12 road network as they cannot take into account area-specific characteristics (geographic,

13 cultural etc.) that may differentiate the outcomes. Consequently, to predict the impact of

14 a future speed limit increase on a specific road network it is necessary define the current

15 crash-speed relationship on it. Based on the amount of the kinetic energy that is released

16 during a collision, crashes that occur under high speed conditions are definitely more

17 likely to lead to more serious outcomes (Joksch 1993; Aarts and Van Schagen 2006;

18 Pei, Wong, and Sze 2012). Speed is also considered to be related with higher crash

19 frequency. That is mainly because high speeds are related with longer stopping

20 distances and increased probability of loss of control or other errors (Kloeden et al.

21 1997; Elvik, Christensen, and Amundsen 2004). Although there is a considerable

22 amount of research on this topic, there are several points of disagreement between

23 studies. A number of researchers suggest that speed and crash frequency are

24 proportional (Taylor, Lynam, and Baruya 2000; Fildes, Rumbold, and Leening 1991),

25 however others did not find any statistically significant relationship between them 
1 (Kockelman and Ma 2007; Quddus 2013). Additionally, a few studies contradicted the

2 common belief, proposing that speed is inversely proportional with crashes (Baruya

3 1998b; Stuster 2004).

4

A source of variability in the research outcomes might be the information losses caused by the conventional crash data aggregation approaches that employ spatial criteria, such as the link-based method. In link-based models all the crashes that occurred on a road link during the study period are grouped and analysed together under the strong assumption that they are all related with the average traffic conditions on the link. This method is related with data aggregation problems (Black, Hashimzade, and Myles 2009; Davis 2004, Imprialou et al. forthcoming) and limited potential to represent the actual traffic conditions that are related with crashes which are very likely to be extreme (Hossain and Muromachi 2013; Pande and Abdel-Aty 2005). Most of the studies that examine crash frequency as a function of speed employ the total number of crashes that occurred on a network. However, different crash mechanisms could be by definition related with different traffic circumstances (D. G. Kim, Washington, and Oh 2006). As a consequence, the examination of crash contributory factors to an aggregate level might distort the results of the analyses. Researchers who studied the effects of crash contributory factors for different crash types (defined by the number of involved vehicles and/or the point of the first impact) confirm that there are indeed significant variations in the estimated coefficients between crash types （Qin, Ivan, and Ravishanker 2004; D. G. Kim, Washington, and Oh 2006; Ye et al. 2009; Bham, Javvadi, and Manepalli 2012; Geedipally, Patil, and Lord 2010; Ivan, Pasupathy, and Ossenbruggen 1999; Ivan, Wang, and Bernardo 2000). Single vehicle (henceforth: SV) crashes are found to be related with low density traffic conditions in contrast to multiple vehicle (henceforth: MV) crashes that are associated 
1 with peak periods, higher volume and density (Ivan, Pasupathy, and Ossenbruggen

2 1999; Ivan 2004; Ivan, Wang, and Bernardo 2000). Therefore, the separate examination

3 of speed with SV and MV crashes is logical and justified. A limitation of the previous

4 studies was the use of separate regression models for each crash type. This approach

5 ignores possible correlations between different crash types that can potentially lead to

6 imprecise estimations(Park and Lord 2007). This can be addressed using multivariate

7 Poisson or Poisson lognormal models that have been proposed for modelling

8 simultaneously multiple crash categories while controlling for their correlations (e.g.

9 Ma and Kockelman 2006; Ma, Kockelman, and Damien 2008; Aguero-Valverde and

10 Jovanis 2009; Park and Lord 2007; El-Basyouny and Sayed 2009; Barua, El-Basyouny,

11 and Islam 2014; Aguero-Valverde 2013). At most of the cases, multivariate models

12 have been shown to have improved fit to the data compared to univariate models and

13 that is why they are considered to provide more accurate outcomes (Barua, El-

14 Basyouny, and Islam 2014; Ma, Kockelman, and Damien 2008).

15 This paper defines the relationship of speed with crashes on the UK motorway

16 by developing a modelling approach that eliminates aggregation problems, which is the

17 main limitation of the link-based models, and takes into account the correlations

18 between the two examined crash types using multivariate Poisson lognormal regression.

19 Crashes are grouped according to the resemblance of the prevailing traffic conditions

20 just before their occurrence which are identified based on their geo-coded crash

21 locations. The crash counts are divided by crash type such as single vehicle crashes and

22 multiple vehicles crashes and by severity and are modelled simultaneously using

23 multivariate Poisson lognormal regression in a full Bayes framework. Through the

24 development of the crash-speed relationships, the impact of a potential average speed

25 increase caused by a speed limit raise from $70 \mathrm{mph}$ to $80 \mathrm{mph}$ is quantified. 


\section{Data preparation}

\section{$2 \quad 3.1 \quad$ Data}

3 The data that were synthesized for the statistical analysis were obtained from: a) the

4 National Road Crash Database of the United Kingdom (STATS 19) (Department for

5 Transport 2011b), b) the UK Highways Agency Journey Time Database (JTDB)

6 (Highways Agency 2011) and c) the UK Highways Agency Traffic speed condition

7 survey (TRACS) (Highways Agency 2008). Each of these datasets is briefly discussed

8 below.

\section{$9 \quad 3.1 .1 \quad$ Crash Data}

10 The examined crash data consisted of 5,606 crashes that occurred on the motorway

11 network of England (total length approximately 3,519 km, typical speed limit $70 \mathrm{mph}$ )

12 during 2012. STATS 19 crash reports include all injury crashes and are divided into

13 crashes with fatal, serious and slight injuries. The variables that were extracted from

14 STATS19 for the purpose of this analysis are crash date, time, location, number of

15 vehicles involved and vehicles' intended direction prior to the crash. Considering the

16 different intrinsic characteristics of collisions, crashes will be examined separately by

17 type. Crashes were divided according to the number of involved vehicles into: a) single

18 vehicle crashes (SV) and b) main carriageway multiple vehicle crashes (MV).

19 Intersection MV crashes (defined as crashes where the colliding vehicles had different

20 intended directions) were eliminated from the analysis for two reasons. Firstly, the

21 small number of observations (4.6\% of all motorway crashes) did not permit the

22 formation of an individual category that was suitable for count regression models.

23 Secondly, intersection crashes could not be merged with the main carriageway multiple

24 vehicle collisions as these types are assumed to have significantly different generation 
1 processes. The final number of valid crash observations was 4,505 crashes $^{1}$ due to

2 missing and/or illogical values either in the crash, traffic or geometry datasets.

3 Crash location is a key component for the identification of the traffic and

4 geometric conditions just before a crash; however, the reported crash locations were less

5 accurate than desired. To overcome this limitation, crashes were allocated to refined and

6 more accurate locations based on the output of a fuzzy-logic based crash mapping

7 algorithm which employs some of the most common crash location information

8 (Imprialou, Quddus, and Pitfield 2014). The algorithm was developed for the study area

9 and provides $98.9 \%( \pm 1.1 \%)$ accurate crash locations.

$10 \quad 3.1 .2 \quad$ Traffic data

11 Traffic conditions were obtained from the JTDB that stores link-level traffic data

12 (obtained from inductive loops) of the UK motorway network in 15-minute intervals.

13 The traffic variables used here were the average speed $(\mathrm{km} / \mathrm{h})$ and the volume (vehicles)

14 per 15 minutes.

\section{$15 \quad$ 3.1.3 Geometric data}

16 Road geometry was obtained by the TRACS surveys that measure road geometrical

17 characteristics using survey vehicles. The data used here were the radius and gradient

18 measured in a 10-metre span for the entire UK motorway network.

${ }^{1}$ Out of the 4,505 crashes included in the analysis 1,060 were single vehicle (184 fatal or serious and 876 slight) and 3,445 were multiple vehicle (302 fatal or serious and 3143 slight). 


\subsection{Condition-based datasets}

In link-based approaches crashes are gathered into groups based on the location

3 of their occurrence. As it has been stated before, this default feature of this method

4 might influence the outcomes and restrict the explanatory potential of the models. In

5 this paper, to overcome this limitation crashes are aggregated in an alternative way.

6 Instead of their locations, the examined crashes are grouped according to the similarities

7 of the traffic and geometric road conditions just before their occurrence forming a

8 different crash count dataset termed as condition-based (see also Imprialou et al.

9 forthcoming). To generate a condition-based dataset the combination of the crash,

10 traffic and geometry data in a form suitable for the statistical analysis is required. Each

11 observation of the condition-based dataset represents an individual scenario of traffic

12 and geometric conditions. The final dataset consists of every possible condition scenario

13 that could occur on the road network during the study period. The condition scenarios

14 were formed by combining the following variables:

- Speed: Speed was divided into 50 groups of equal frequency with a 2-percentile step (e.g. $2^{\text {nd }}-4^{\text {th }}$ percentile of speed observations) and was represented as a continuous variable by the median of each group.

- Volume: Separately for each of the 50 speed groups, the volume was divided into 4 intervals of equal frequency (i.e. the quartiles of volume observations) resulting in a total of 200 unique values and was represented as a continuous variable by the median of each interval.

- Curvature: Sections with curved or straight sections (dummy variable);

- Gradient: Uphill, downhill or level sections (categorical variable);

- Number of lanes: Sections with up to two lanes per direction or over two lanes per direction (dummy variable). 
2 2,400 scenarios which traffic conditions appeared with equal frequency on the study

3 network. Following, each scenario of the dataset was matched with a number of crashes

4 (if any) that occurred under its corresponding traffic and geometric conditions

5 (dependent variable). To do this, each crash was individually classified to the condition

6 scenario that described best the road circumstances prior its occurrence.

7 Traffic conditions on the road section where the crashes occurred were identified

8 based on the reported date and time of the crash. The road segment that was assumed to

9 be the most influential for the crash occurrence was considered to be equal with the

10 length of the average stopping distance upstream of the crash location increased by 20

11 metres downstream to correct for minor errors related with the crash location

12 identification (final considered segment length: 117 metres). Based on the TRACS

13 measurements, each segment was characterised as curved or straight and uphill,

14 downhill or level.

15 After the classification of crashes to specific condition scenarios, each scenario

16 included crash counts split by crash type (i.e. SV, MV) and by severity. To control for

17 the unequal likelihood of crash occurrences between scenarios the measure of exposure

18 that was considered as more suitable was the average vehicle hours travelled per mile

19 for each scenario. The descriptive statistics of the dataset can be found at Table 1.

\section{Methodology}

21 Crash counts by collision type cannot be assumed to be independent because they are

22 subsets of the total crashes that occurred on a road network. Therefore, modelling them

23 separately might lead to inaccurate estimations of standard errors (Park and Lord 2007).

24 Multivariate Poisson Log Normal (MVPLN) regression is proposed for modelling

25 categorised crash counts (e.g. by collision type or severity level) while controlling for 
1 over-dispersion and the correlations between the categories (Park and Lord 2007; Ma,

2 Kockelman, and Damien 2008; El-Basyouny and Sayed 2009; Aguero-Valverde and

3 Jovanis 2009).

4 In a condition-based dataset with $n$ pre-crash scenarios the number of crashes

5 per category can be considered to follow a Poisson distribution with a lognormally

6 distributed parameter:

$$
y_{i k} \sim \operatorname{Poisson}\left(\lambda_{i k}\right), \quad \mathrm{i}=1,2, \ldots, \mathrm{n}, \mathrm{k}=1,2, \ldots, \mathrm{K}
$$

7 Where $i$ :index of observation, $k$ : index of crash category, $y_{i k}$ :observed number of

8 crashes of the category $k$ for the $i^{\text {th }}$ observation and $\lambda_{i k}$ : the expected mean of

9 crashes of category $k$ for the for the $i^{\text {th }}$ observation. The link function of the model 10 is:

$$
\ln \left(\lambda_{i k}\right)=\beta_{k 0}+\sum_{m=1}^{m} \beta_{k m} X_{i k m}+\ln \left(e_{i}\right)+\varepsilon_{i k}
$$

11 Where $\beta_{k 0}$ : intercept for category $k, \beta_{k m}$ : coefficient of the $\mathrm{m}^{\text {th }}$ explanatory

12 variable and category $k, X_{i k m}$ : value of the $\mathrm{m}^{\text {th }}$ explanatory variable for the $i^{t h}$

13 observation and category $k, e_{i}$ : exposure variable and $\varepsilon_{i k}$ :unobserved

14 heterogeneity for the for the $i^{\text {th }}$ observation and category $k . \varepsilon_{i}$ is multivariate

15 normally distributed so as to control for the correlations within the unobserved

16 heterogeneity:

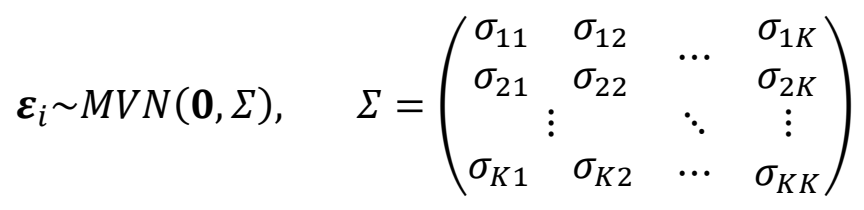


1 Where $\Sigma$ is the variance-covariance matrix (i.e. precision matrix) of the

2 unobserved heterogeneity.

3 The models' parameters were estimated using Markov chain Monte Carlo (MCMC)

4 in a Bayesian framework. The prior distribution for $\beta$ was multivariate normal and

5 the conjugate prior distribution of the precision matrix was Wishart as it has been

6 suggested in the literature (e.g. Aguero-Valverde and Jovanis 2009; Ma,

7 Kockelman, and Damien 2008; Park and Lord 2007):

$$
\begin{gathered}
\beta \sim M V N\left(\beta_{0}, R_{\beta_{0}}\right) \\
\Sigma^{-1} \sim \operatorname{Wishart}(R, d)
\end{gathered}
$$

9 Where $\beta_{0}, R_{\beta_{0}}, R$ are non-informative hyperparameters and $d$ represents the 10 degrees of freedom (i.e. $d=k$ ).

11 The model presented in equation (8) was applied separately to:: (i) all crashes

12 split by crash type (henceforth: CT) (i.e. all SV and all MV crashes), (ii) SV crashes

13 disaggregated by severity (henceforth: SV_sev) (i.e. SV crashes with killed and serious

14 injuries combined ${ }^{2}$ and slight injury crashes), (iii) MV crashes split by severity

15 (henceforth: MV_sev) (i.e. MV crashes with killed and serious injuries combined and

16 slight injury crashes). The actual functional form of the relationships of speed and

17 volume with crashes is unknown (Qin, Ivan, and Ravishanker 2004). In order to

18 examine the validity of the assumption that the relationship of crashes with speed and

\footnotetext{
${ }^{2}$ Fatal and serious crashes were combined into one category due to the very low number of observations for fatal crashes (i.e. 25 out of 1060 for SV and 36 out of 3445).
} 
1 volume is necessarily linear, 18 different specifications ${ }^{3}$ for speed and volume were

2 tested. The models that are presented in the following section have the best fitting

3 specification among all the examined specifications (based on the Deviance Information

4 Criterion).

\section{$5 \quad 5 \quad$ Results and discussion}

\section{$6 \quad 5.1 \quad$ Modelling outcomes}

7 Three models were estimated with the MCMC method using WinBUGS software

8 (Spiegelhalter et al. 2003) that is suitable for multivariate models with the full Bayesian

9 approach. The estimations were derived from 50,000 iterations of two chains with a

10 burn-in sample of 20,000. Convergence was visually detected by observing the trace

11 plots of the estimates. The best fitting specification was different for each of the three

12 models; more specifically CT was best described by a linear speed, the natural

13 logarithm of volume and an interaction term (i.e. Speed*Volume) (i.e. specification 12),

14 SV_sev by the square of speed and the logarithm of volume (i.e. specification 3) and

15 MV_sev by linear speed, squared volume and an interaction term (i.e. specification 11).

16 Tables 2-4 present the coefficient estimates for CT, SV_sev and MV_sev respectively.

17 In order to clarify the outcomes, especially for the models that have interaction terms,

${ }^{3} 3$ 1. speed, volume; 2. speed, volume ${ }^{2}$; 3. speed, $\ln$ (volume); 4. speed ${ }^{2}$, volume; 5. speed ${ }^{2}$, volume$^{2}$; 6. speed $^{2}$, n(volume); 7. $\ln$ (speed), volume; 8. $\ln \left(\right.$ speed), volume ${ }^{2}$; 9. $\ln ($ speed), $\ln \left(\right.$ volume); 10. speed, volume, speed*volume; 11. speed, volume ${ }^{2}$, speed*volume; 12. speed, $\ln \left(\right.$ volume), speed*volume; 13. speed ${ }^{2}$, volume, speed*volume; 14 . speed ${ }^{2}$, volume ${ }^{2}$, speed*volume; 15. speed ${ }^{2}, \ln ($ volume), speed*volume; $16 . \ln ($ speed),volume, speed*volume; 17. $\ln \left(\right.$ speed), volume ${ }^{2}$, speed*volume; $18 . \ln$ (speed), $\ln ($ volume) , speed*volume; 
1 Figures 1a, 1c, 4a, 4c, 7a and 7c depict the relationship of speed with crash rates for 3

2 distinct volumes. Similarly, Figures $1 \mathrm{~b}, 1 \mathrm{~d}, 4 \mathrm{~b}, 4 \mathrm{~d}, 7 \mathrm{~b}$ and $7 \mathrm{~d}$ represent the relationship

3 of volume with crash rates for three different speeds. Figures 2, 3, 5, 6, 8 and 9 show the

4 relationship of crash rates with speed and volume combined in a 3D format. Comparing the coefficient values of the SV with those of the MV (Table 2,

6 Figure 1, Figure 2 and Figure 3) it is clear that the two crash types tend to occur under 7 significantly different traffic conditions on the roadway. SV collisions increase while 8 speed increases and volume decreases; in other words, they tend to occur more

9 frequently at lower density conditions. On the other hand, MV collisions seem to be

10 related with lower speeds and higher volumes and consequently with more intense

11 traffic. In principle, this outcome, that is in line with the existing literature (Ivan, Wang, 12 and Bernardo 2000; Ivan, Pasupathy, and Ossenbruggen 1999; Ivan 2004), re-confirms

13 that modelling crashes by type is advantageous as it can be more informative about the

14 circumstances that particular crashes types occur. However, interpreting these results

15 without looking at the effect of speed on different severity levels by crash type might be 16 misleading, especially for the case of MV crashes.

17 The frequency of SV crashes is independent of the severity of their outcomes 18 and increases proportionally with speed (Table 3, Figure 4, Figure 5 and Figure 6). The 19 coefficients of speed for KSI and SL crashes show that, as expected, higher speed is 20 also related with more serious injuries. Traffic volume has exactly the opposite effect to 21 SV crashes, as the highest crash rate is observed at lower volumes, a finding that is 22 consistent with previous studies (e.g. Qin, Ivan, and Ravishanker 2004; Ivan 2004). The 23 results of the SV_sev model are explainable as SV crashes are probably the most speed-

24 related crash type. SV crashes are associated with loss of control, alcohol or drug 25 impaired drivers, risk-taking actions, fatigue and sleepiness (Xie, Zhao, and Huynh 
1 2012; J. K. Kim et al. 2013; Lang, Waller, and Shope 1996). They usually occur during

2 off-peak times and especially at night time when density is at low levels and vehicle

3 encounters are less likely (Ivan, Pasupathy, and Ossenbruggen 1999). Thus, SV crashes

4 are expected to be more and more serious after an average speed limit increase.

Despite the initial findings of the CT model, MV crashes are found to have

6 different relationships with traffic conditions when they are disaggregated by severity

7 level (Table 4, ,Figure 7, Figure 8 and Figure 9). The outcome of the CT model reflects

8 mainly the relationship of the majority of MV crashes that accounted for slight injuries.

9 Slight injury MV crashes seem to have a negative relationship with speed while their

10 relationship with volume can be described by a U-shaped curve (Figure 9) meaning that

11 this crash type tends to occur mainly at very low and very high volume conditions. This

12 outcome can be explained considering the characteristics of the two main collision types

13 of MV same direction crashes: side and rear-end collisions. Side impacts are more

14 likely to occur during overtaking manoeuvres that are more frequent under lower

15 density conditions. On the contrary, rear-end collisions are linked with more dense

16 conditions. This is consistent with previous findings that suggest that high traffic

17 intensity and peak hours are related with more MV crashes (Ivan 2004; Ivan,

18 Pasupathy, and Ossenbruggen 1999). Fatal and serious injury MV crash rate, though, is

19 generally proportional to speed apart from very high volume conditions ${ }^{4}$. This is in line

20 with existing studies that suggest that crashes with serious impact tend to be positively

21 related with speed (e.g. Aarts and Van Schagen 2006). This result may reflect the

\footnotetext{
${ }^{4}$ When the 15-minute volume per lane is above 278 vehicles (estimated based on the slope equation for speed). This corresponds to volumes higher than the $83^{\text {rd }}$ percentile of all observations.
} 
1 differences of the two major same direction crash types but it might also be the effect of

2 the merger of fatal and serious crashes into one category. If it would be possible to

3 estimate a separate model for fatal crashes, speed would have probably shown a

4 positive relationship with fatal crashes. .

Road geometry was mainly found to have similar impact on both SV and MV

6 crashes, as the coefficients were consistent for all types and severities. Locations with

7 curvature and steep horizontal alignment (especially downgrades) tend to concentrate

8 more crashes, a finding that is similar with previous literature (Milton and Mannering

9 1998; Abdel-Aty and Radwan 2000; Anastasopoulos and Mannering 2009). Roads with

10 more lanes are found to be more related with crash occurrences too. This can be

11 explained especially for MV crashes by the fact that wider roads are more prone to lane

12 changing that is related with increased and potentially dangerous vehicle encounters

13 (e.g. Chang 2005).

\section{$14 \quad 5.2 \quad$ Impact estimation}

Apart from explaining the relationship of crashes with traffic and geometry

16 related variables, the developed models are employed to predict the impact of speed

17 limit changes on traffic crashes. Using the elasticity of crashes with respect to speed it is

18 possible to estimate the expected changes in the number of crashes by type and severity

19 as a result of a speed limit increase. According to existing literature the average speed

20 on a road is expected to rise by $25 \%$ to $50 \%$ of the amount of the speed limit increase

21 (e.g. Rock 1995; Finch et al. 1994). This means that if the speed limit of UK motorways

22 increases from $70 \mathrm{mph}$ to $80 \mathrm{mph}$ (i.e. $10 \mathrm{mph}$ ) the average speed would be expected to

23 increase by $2.5 \mathrm{mph}$ to $5 \mathrm{mph}$. However, it is not clear how this change would affect the

24 speed distribution of the network. A speed limit change could cause a uniform shift to

25 the speed distribution, or it could cause a more significant increase at higher speed 
1 conditions than at the lower ones. Considering that low speeds are normally related with

2 traffic congestion, the second case is likely to be more representative. Since it is not

3 possible to predict the form of the new speed distribution, the elasticity values that are

4 presented in this paper are estimated based on the expected changes on the average

5 speed. The equation of the mean elasticity of the $m^{\text {th }}$ variable of the $k^{\text {th }}$ category is:

$$
\text { Elasticity }=\frac{\partial E\left(y \mid x_{m k}\right)}{\partial x_{m k}} * \frac{x_{m k}}{y}
$$

Table 5 shows the mean elasticity of speed and the estimated minimum and

7 maximum percentage of increase for SV and MV crashes based on the outcomes of the

8 SV_sev and the MV_sev models respectively. As discussed, a $10 \mathrm{mph}$ increase in speed

9 limit would result in a 3.86\% in average speed rise (i.e. the average speed $64.7 \mathrm{mph}$

10 would at least increase by $2.5 \mathrm{mph}$ ). Given that the mean elasticity of crashes with

11 respect to speed is 2.595 for SV KSI crashes (see Table 5), the corresponding increase

12 in these crash type would be at least $10.02 \%$ (i.e. $3.86 * 2.595$ ) as shown in Table 5 . In a

13 similar manner, SV SL and MV KSI crashes would have an increase of 6.14\% (i.e.

$143.86 * 1.590$ ) and $3.42 \%$ (i.e. $3.86 * 0.886$ ) respectively. The speed elasticity for slight

15 injury MV crashes was chosen not to be presented here. As the relationship of speed

16 with this crash type is negative, the elasticity of speed is a negative, too. Having no

17 evidence to support that a speed limit increase can be associated with decrease in

18 particular types of crashes and to keep the results conservative it is considered that the

19 number of MV crashes that lead to slight injuries will not change.

20 Assuming that all other variables remain the same, single vehicle KSI are

21 expected to increase by $10.0 \%-20.1 \%$ after the first year of implementation of the

22 measure and for SL this number will fluctuate from $6.2 \%$ to12.39\%. This means that

23 after a speed limit increase there will be 73-146 more SV occurrences on the UK 
1 motorway. The increase of MV crashes will be from 3.4\%-6.9\%\% equivalent to 11-21

2 more MV crashes. The overall predicted increase due to the anticipated average speed

3 raise for all KSI and SL crashes will reach 6.2\%-12.1 \% and 1.3\% -2.7\% respectively,

4 indicating that a change on the current speed limit will clearly have a considerable and

5 adverse impact on road safety.

\section{Conclusion}

7 Changes in speed regulation laws lead to changes of the traffic conditions that might

8 affect the levels of safety on road networks. To predict the impact related with such

9 measures it is necessary to understand the relationship of speed with crashes on the

10 examined network. This paper explores the relationship of speed with single vehicle and

11 same direction multiple vehicle crashes on the UK motorways so as to evaluate the

12 effect of a potential $10 \mathrm{mph}$ increase of the current $70 \mathrm{mph}$ speed limit. The speed-crash

13 relationship is described through three condition-based multivariate Poisson lognormal

14 regression models that provide different coefficients by type and severity of the crashes

15 respectively.

16 The results of the models show that speed is positively related with all single

17 vehicle crashes and the fatal or serious multiple vehicle crashes but negatively related

18 with multiple vehicle crashes with slight injuries. This outcome suggests that the UK

19 motorway is likely to have $6.2-12.1 \%$ more fatal or serious crashes and $1.3-2.7 \%$ more

20 slight injury crashes during the first year of the new speed limit implementation,

21 confirming the concerns about the appropriateness of this measure. Taking into

22 consideration that speed limit increases tend to be linked with increases in average

23 speeds on contiguous roads (i.e. spillover effect), the overall crash rise might be even

24 higher than the estimated. As a consequence, a speed limit increase, in the absence of 
new and effective preventive measures, does not seem to be a reasonable idea assuming

that road safety is one the first priorities for policy makers and other stakeholders.

Instead, a reduction of the current number of speed limit violations, that could be

achieved through improvements in enforcement, would be beneficial as it would lead to

a decrease of crashes and the severity of their outcomes.

\section{References}

Aarts, Letty, and Ingrid Van Schagen. 2006. "Driving Speed and the Risk of Road Crashes: A Review.” Accident Analysis \& Prevention Prevention 38 (2): 215-24.

Abdel-Aty, M, and A E Radwan. 2000. "Modeling Traffic Accident Occurrence and Involvement.” Accident Analysis \& Prevention 32 (5): 633-42.

Aguero-Valverde, Jonathan. 2013. "Multivariate Spatial Models of Excess Crash Frequency at Area Level: Case of Costa Rica.” Accident Analysis \& Prevention 59: 365-73.

Aguero-Valverde, Jonathan, and Paul P. Jovanis. 2009. "Bayesian Multivariate Poisson Lognormal Models for Crash Severity Modeling and Site Ranking."

Transportation Research Record: Journal of the Transportation Research Board 2136 (December): 82-91.

Aljanahi, A A, AH Rhodes, and A V Metcalfe. 1999. "Speed, Speed Limits and Road Traffic Accidents under Free Flow Conditions.” Accident Analysis \& Prevention 31 (1-2): 161-68.

Anastasopoulos, Panagiotis Ch, and Fred L Mannering. 2009. “A Note on Modeling Vehicle Accident Frequencies with Random-Parameters Count Models.” Accident Analysis \& Prevention 41 (1): 153-59.

Barua, Sudip, Karim El-Basyouny, and Md Tazul Islam. 2014. “A Full Bayesian Multivariate Count Data Model of Collision Severity with Spatial Correlation.” Analytic Methods in Accident Research 3-4. Elsevier: 28-43.

Baruya, A. 1998a. "Speed-Accident Relationships on European Roads.” In 9th International Conference Road Safety in Europe. Vol. 1. Bergisch Gladbach, Germany.

Baruya, A. 1998b. MASTER: Speed-Accident Relationship on European Roads. Vol. 67. UK.

Bham, Ghulam H., Bhanu S. Javvadi, and Uday R. R. Manepalli. 2012. "Multinomial Logistic Regression Model for Single-Vehicle and Multivehicle Collisions on 
Urban U.S. Highways in Arkansas.” Journal of Transportation Engineering 138 (June): 786-97.

Black, John, Nigar Hashimzade, and Gareth Myles. 2009. A Dictionary of Economics. Oxford University Press.

Chang, Li-Yen. 2005. “Analysis of Freeway Accident Frequencies: Negative Binomial Regression versus Artificial Neural Network.” Safety Science 43 (8): 541-57.

Clark, Wav, and Kl Avery. 1976. "The Effects of Data Aggregation in Statistical Analysis.” Geographical Analysis 8 (4): 428-38.

Davis, Gary A. 2004. "Possible Aggregation Biases in Road Safety Research and a Mechanism Approach to Accident Modeling.” Accident Analysis \& Prevention 36 (6): 1119-27.

Department for Transport. 2006. Setting Local Speed Limits. Department for Transport, London, England.

Department for Transport. 2011a. "Government Proposes 80MPH Motorway Speed Limit - Announcements.” Department for Transport. https://www.gov.uk/government/news/government-proposes-80mph-motorwayspeed-limit.

Department for Transport. 2011b. “STATS19 Road Accident Injury Statistics - Report Form.” https://www.gov.uk/government/uploads/system/uploads/attachment_data/file/ 23 0590/stats19.pdf.

Department for Transport. 2014. Free Flow Vehicle Speed Statistics : Great Britain 2013. London, England.

El-Basyouny, Karim, and Tarek Sayed. 2009. "Collision Prediction Models Using Multivariate Poisson-Lognormal Regression.” Accident Analysis \& Prevention 41 (4): 820-28.

Elvik, Rune. 2009. The Power Model of the Relationship between Speed and Road Safety: Update and New Analyses. TØI Report. Vol. 1034.

Elvik, Rune, Peter Christensen, and Astrid Amundsen. 2004. "Speed and Road Accidents. An Evaluation of the Power Model.” TØI Report 740 (December). Oslo: 2004.

Fildes, B N, G Rumbold, and A Leening. 1991. Speed Behaviour and Drivers’'Attitude to Speeding. Monash University Accident Research Centre, Report. Vol. 16. Victoria,Austalia.

Finch, D J, P Kompfner, C R Lockwood, and G Maycock. 1994. Project Report 58Speed, Speed Limits and Accidents. Crowthorne, England. 
Freedman, Mark, and Allan F Williams. 1992. "Speeds Associated with 55- Mph and 65-Mph Speed Limits in NortheasternStates.” ITE Journal 62 (2): 17-22.

Geedipally, Srinivas Reddy, and Dominique Lord. 2010. "Investigating the Effect of Modeling Single-Vehicle and Multi-Vehicle Crashes Separately on Confidence Intervals of Poisson-Gamma Models.” Accident Analysis \& Prevention 42 (4). Elsevier Ltd: 1273-82.

Geedipally, Srinivas Reddy, Sunil Patil, and Dominique Lord. 2010. "Examination of Methods to Estimate Crash Counts by Collision Type.” Transportation Research Record: Journal of the Transportation Research Board 2165: 12-20.

Hauer, Ezra, and James Bonneson. 2006. An Empirical Examination of the Relationship Between Speed and Road Accidents. Unpublished manuscript dated March 5, 2006.

Highways Agency. 2008. "Pavement Design \& Maintenance.” In Design Manual for Roads and Bridges. Department for Transport, UK.

Highways Agency. 2011. HATRIS JTDB Reference Manual. https://jtdb.hatris.co.uk/NJTDB Reference manual.pdf.

Hossain, Moinul, and Yasunori Muromachi. 2013. "Understanding Crash Mechanism on Urban Expressways Using High-Resolution Traffic Data.” Accident Analysis \& Prevention 57 (August). Elsevier Ltd: 17-29.

Imprialou, Maria-Ioanna M., Mohammed Quddus, and David E. Pitfield. 2014. "High Accuracy Crash Mapping Using Fuzzy Logic.” Transportation Research Part C: Emerging Technologies 42 (May). Elsevier Ltd: 107-20.

Imprialou, Maria-Ioanna M., Mohammed Quddus, David E. Pitfield and Dominique Lord. 2015. "Re-visiting crash-speed relationships: A new perspective in crash modelling." Accident Analysis \& Prevention. http://dx.doi.org/10.1016/j.aap.2015.10.001

Ivan, John N. 2004. "New Approach for Including Traffic Volumes in Crash Rate Analysis and Forecasting." Transportation Research Record 1897: 134-41.

Ivan, John N, Chunyan Wang, and Nelson R Bernardo. 2000. "Explaining Two-Lane Highway Crash Rates Using Land Use and Hourly Exposure.” Accident Analysis \& Prevention 32 (6): 787-95.

Ivan, John N., Raghubhushan K. Pasupathy, and Paul J. Ossenbruggen. 1999. "Differences in Causality Factors for Single and Multi-Vehicle Crashes on TwoLane Roads.” Accident Analysis \& Prevention 31 (6): 695-704.

Joksch, Hans C. 1993. "Velocity Change and Fatality Risk in a crash-A Rule of Thumb.” Accident Analysis \& Prevention 25 (1): 103-4.

Kim, Do Gyeong, Yuhwa Lee, Simon Washington, and Keechoo Choi. 2007. "Modeling Crash Outcome Probabilities at Rural Intersections: Application of 
Hierarchical Binomial Logistic Models.” Accident Analysis and Prevention 39 (1): 125-34.

Kim, Do Gyeong, Simon Washington, and Jutaek Oh. 2006. "Modeling Crash Types: New Insights into the Effects of Covariates on Crashes at Rural Intersections." Journal of Transportation Engineering 132: 282-92.

Kim, Joon Ki, Gudmundur F. Ulfarsson, Sungyop Kim, and Venkataraman N. Shankar. 2013. "Driver-Injury Severity in Single-Vehicle Crashes in California: A Mixed Logit Analysis of Heterogeneity due to Age and Gender.” Accident Analysis \& Prevention 50. Elsevier Ltd: 1073-81.

Kloeden, C.N., A.J McLean, and G Glonek. 2002. Reanalysis of Travelling Speed and the Risk of Crash Involvement in Adelaide South Australia. No CR 207, NHMRC Road Accident Research Unit, The University of Adelaide.

Kloeden, C.N., A.J. Mclean, V.M. Moore, and G Ponte. 1997. Travelling Speed and the Risk of Crash Involvement Volume 1 - Findings. No CR 172, NHMRC Road Accident Research Unit, The University of Adelaide. Vol. 1. South Australia.

Kockelman, Kara M, and Jianming Ma. 2007. "Freeway Speeds and Speed Variations Preceding Crashes , Within and Across Lanes.” Transportation Research Forum 46 (1): 43-61.

Lang, Sylvia Wanner, Patricia F. Waller, and Jean Thatcher Shope. 1996. "Adolescent Driving: Characteristics Associated with Single-Vehicle and Injury Crashes.” Journal of Safety Research 27 (4): 241-57.

Ma, Jianming, and Kara M Kockelman. 2006. "Bayesian Multivariate Poisson Regression for Models of Injury Count, by Severity.” Transportation Research Record 1950: 24-34.

Ma, Jianming, Kara M Kockelman, and Paul Damien. 2008. “A Multivariate PoissonLognormal Regression Model for Prediction of Crash Counts by Severity, Using Bayesian Methods.” Accident Analysis \& Prevention 40 (3): 964-75.

Milton, John, and Fred Mannering. 1998. "The Relationship among Highway Geometrics , Traffic-Related Elements and Motor-Vehicle Accident Frequencies.” Transportation 25 (6): 395-413.

Nilsson, Goran. 2004. "Traffic Safety Dimensions and the Power Model to Describe the Effect of Speed on Safety.” Lund Institute of Technology and Society, Traffic Engineering, 2004.

Pande, Anurag, and Mohamed Abdel-Aty. 2005. "A Freeway Safety Strategy for Advanced Proactive Traffic Management.” Journal of Intelligent Transportation Systems: Technology, Planning, and Operations 9 (3): 145-58. 
Park, Eun Sug, and Dominique Lord. 2007. "Multivariate Poisson-Lognormal Models for Jointly Modeling Crash Frequency by Severity." Transportation Research Record: Journal of the Transportation Research Board 2019 (December): 1-6.

Pei, Xin, S C Wong, and N N Sze. 2012. "The Roles of Exposure and Speed in Road Safety Analysis.” Accident Analysis \& Prevention 48 (September). Elsevier Ltd: $464-71$.

Qin, Xiao, John N. Ivan, and Nalini Ravishanker. 2004. "Selecting Exposure Measures in Crash Rate Prediction for Two-Lane Highway Segments.” Accident Analysis \& Prevention 36: 183-91.

Quddus, Mohammed. 2013. "Exploring the Relationship Between Average Speed, Speed Variation, and Accident Rates Using Spatial Statistical Models and GIS.” Journal of Transportation Safety \& Security 5 (1): 27-45.

Rock, S M. 1995. "Impact of the 65 Mph Speed Limit on Accidents, Deaths, and Injuries in Illinois.” Accident Analysis \& Prevention 27 (2): 207-14.

Spiegelhalter, David, Andrew Thomas, Nicky Best, and Dave Lunn. 2003. "WinBUGS User Manual.” version.

Stuster, Jack. 2004. Aggressive Driving Enforcement: Evaluations of Two Demonstration Programs. Report DOT HS 809 707. Washington DC.

Taylor, M C, D A Lynam, and A Baruya. 2000. The Effects of Drivers' Speed on the Frequency of Road Accidents. Transport Research Laboratory, Crowthorne, England.

TRB. 1998. Managing Speed: Review of Current Practice for Setting and Enforcing Speed Limits. Special Report 254. Transportation Research Board, Washington D.C.

Xie, Yuanchang, Kaiguang Zhao, and Nathan Huynh. 2012. "Analysis of Driver Injury Severity in Rural Single-Vehicle Crashes.” Accident Analysis \& Prevention 47. Elsevier Ltd: 36-44.

Ye, Xin, Ram M. Pendyala, Simon P. Washington, Karthik Konduri, and Jutaek Oh. 2009. "A Simultaneous Equations Model of Crash Frequency by Collision Type for Rural Intersections.” Safety Science 47 (3). Elsevier Ltd: 443-52. 
1 Table 1: Descriptive statistics of the condition-based dataset

\begin{tabular}{|c|c|c|c|c|}
\hline & Mean & $\begin{array}{l}\text { Std. } \\
\text { Dev. }\end{array}$ & Min & Max \\
\hline \multicolumn{5}{|l|}{ Dependent Variables } \\
\hline All_SV & 0.442 & 0.833 & 0 & 7 \\
\hline KSI_SV & 0.077 & 0.292 & 0 & 3 \\
\hline SL_SV & 0.365 & 0.730 & 0 & 7 \\
\hline All_MV & 1.435 & 3.719 & 0 & 80 \\
\hline KSI_MV & 0.203 & 0.548 & 0 & 7 \\
\hline SL_MV & 1.310 & 3.461 & 0 & 75 \\
\hline \multicolumn{5}{|l|}{ Independent Variables } \\
\hline Speed (mph) & 64.692 & 8.301 & 31.771 & 82.282 \\
\hline $\begin{array}{l}\text { Volume per lane (measurement } \\
\text { interval } 15 \text { minutes) }\end{array}$ & $\begin{array}{c}147.92 \\
6 \\
\end{array}$ & 113.694 & 11.000 & 443.000 \\
\hline Curve & 0.500 & 0.500 & 0 & 1 \\
\hline Straight (reference) & 0.500 & 0.500 & 0 & 1 \\
\hline Uphill & 0.333 & 0.472 & 0 & 1 \\
\hline Downhill & 0.333 & 0.472 & 0 & 1 \\
\hline Level (reference) & 0.333 & 0.472 & 0 & 1 \\
\hline Lanes above 2 & 0.500 & 0.500 & 0 & 1 \\
\hline Lanes up to 2 (reference) & 0.500 & 0.500 & 0 & 1 \\
\hline $\begin{array}{l}\text { Vehicle hours per mile } \\
\text { (Exposure) }\end{array}$ & 7.039 & 6.735 & 0.526 & 45.934 \\
\hline
\end{tabular}


1 Table 2: Coefficient estimates of the multivariate Crash Type (CT) model for all crashes 2 (i.e. Single-Vehicle and Multiple-Vehicle)

\begin{tabular}{lccccc}
\hline Single Vehicle & Mean & SD & $\begin{array}{c}\text { MC } \\
\text { error }\end{array}$ & 2.5\% & $\mathbf{9 7 . 5 \%}$ \\
\hline Speed & $0.03153^{*}$ & 0.00442 & 0.00019 & 0.02264 & 0.04043 \\
\hline ln(Volume) & $-0.51640^{*}$ & 0.09412 & 0.00445 & -0.70200 & -0.33480 \\
\hline Speed.Volume & $-0.00004^{*}$ & 0.00001 & 0.0000006 & -0.00006 & -0.00001 \\
\hline Curve & $0.18200^{*}$ & 0.06565 & 0.00070 & 0.05264 & 0.31110 \\
\hline Uphill & $2.08600^{*}$ & 0.16770 & 0.00450 & 1.76600 & 2.43100 \\
\hline Downhill & $2.82200^{*}$ & 0.16300 & 0.00453 & 2.51400 & 3.15700 \\
\hline Lanes above2 & $0.88450^{*}$ & 0.06976 & 0.00076 & 0.74870 & 1.02100 \\
\hline Intercept & $-4.52462^{*}$ & 0.54720 & 0.02643 & -5.10200 & -2.98800 \\
\hline $\begin{array}{l}\text { ln(Vehicle } \\
\text { hours per mile) }\end{array}$ & 1 & - & - & - & - \\
\hline Multiple & Mean & SD & MC & $2.5 \%$ & $\mathbf{9 7 . 5 \%}$ \\
Vehicle & & & error & & \\
\hline Speed & $-0.02902^{*}$ & 0.00257 & 0.00012 & -0.03380 & -0.02375 \\
\hline In(Volume) & $-0.45430^{*}$ & 0.07533 & 0.00385 & -0.59220 & -0.30930 \\
\hline Speed·Volume & $0.00005^{*}$ & 0.000009 & 0.0000004 & 0.00003 & 0.00006 \\
\hline Curve & $0.49500^{*}$ & 0.04231 & 0.00054 & 0.41180 & 0.57790 \\
\hline Uphill & $2.14800^{*}$ & 0.09754 & 0.00261 & 1.96200 & 2.34500 \\
\hline Downhill & $2.87400^{*}$ & 0.09476 & 0.00265 & 2.69400 & 3.06400 \\
\hline Lanes above2 & $1.25500^{*}$ & 0.04675 & 0.00067 & 1.16400 & 1.34600 \\
\hline Intercept & $-1.43880^{*}$ & 0.41250 & 0.02113 & -1.80800 & -0.22700 \\
\hline $\begin{array}{l}\text { In(Vehicle } \\
\text { hours per mile) }\end{array}$ & 1 & - & - & - & - \\
\hline $\begin{array}{l}\text { Dbar } \\
\text { pD } \\
\text { DIC }\end{array}$ & 8199.42 & $*$ significant at the 95\% credible interval & \\
\hline & 809.239 & & & & \\
\hline
\end{tabular}

3 
1 Table 3: Coefficient estimates of the multivariate model for single vehicle crashes by

2 severity (SV_sev)

\begin{tabular}{|c|c|c|c|c|c|}
\hline KSI crashes & Mean & SD & $\begin{array}{c}\text { MC } \\
\text { error }\end{array}$ & $2.5 \%$ & $97.5 \%$ \\
\hline $\begin{array}{l}\text { Speed } \\
\text { Squared }\end{array}$ & $0.00031^{*}$ & 0.00008 & 0.000002 & 0.00016 & 0.00046 \\
\hline $\ln$ (volume) & $-0.80370 *$ & 0.07473 & 0.00206 & -0.95020 & -0.65740 \\
\hline Curve & 0.26960 & 0.15170 & 0.00138 & -0.02645 & 0.56940 \\
\hline Uphill & $1.77200 *$ & 0.34860 & 0.00783 & 1.12900 & 2.49500 \\
\hline Downhill & $2.60000 *$ & 0.33390 & 0.00778 & 1.99000 & 3.30400 \\
\hline Lanes above2 & $0.82470 *$ & 0.16360 & 0.00169 & 0.50910 & 1.15000 \\
\hline Intercept & $-4.37560 *$ & 0.60270 & 0.02098 & -5.08800 & -2.74800 \\
\hline $\begin{array}{l}\ln (\text { Vehicle } \\
\text { hours per } \\
\text { mile) }\end{array}$ & 1 & - & - & - & - \\
\hline SL crashes & Mean & SD & $\begin{array}{c}\text { MC } \\
\text { error }\end{array}$ & $2.5 \%$ & $97.5 \%$ \\
\hline $\begin{array}{l}\text { Speed } \\
\text { Squared }\end{array}$ & $0.00019 *$ & 0.00003 & 0.000001 & 0.00013 & 0.00026 \\
\hline $\ln$ (volume) & $-0.75780^{*}$ & 0.03620 & 0.00102 & -0.82770 & -0.68650 \\
\hline Curve & $0.17010^{*}$ & 0.07105 & 0.00069 & 0.03053 & 0.30880 \\
\hline Uphill & $2.10300 *$ & 0.18000 & 0.00450 & 1.76300 & 2.46900 \\
\hline Downhill & $2.82500 *$ & 0.17500 & 0.00451 & 2.49300 & 3.17900 \\
\hline Lanes above2 & $0.89620^{*}$ & 0.07684 & 0.00082 & 0.74730 & 1.04900 \\
\hline Intercept & $-2.73460 *$ & 0.29220 & 0.01012 & -2.82800 & -1.68700 \\
\hline $\begin{array}{l}\ln (\text { Vehicle } \\
\text { hours per } \\
\text { mile) }\end{array}$ & 1 & - & - & - & - \\
\hline Dbar & 4203.77 & \multirow{3}{*}{\multicolumn{4}{|c|}{ *significant at the $95 \%$ credible interval }} \\
\hline$p D$ & 131.66 & & & & \\
\hline DIC & 4335.43 & & & & \\
\hline
\end{tabular}

3

4

5

6

7 
1 Table 4: Coefficient estimates of the multivariate model for multiple vehicle crashes by

2 severity (MV_ref).

\begin{tabular}{|c|c|c|c|c|c|}
\hline KSI crashes & Mean & SD & MC error & $2.5 \%$ & $97.5 \%$ \\
\hline Speed & $0.030577 *$ & 0.006709 & 0.000277 & 0.017187 & 0.044014 \\
\hline $\begin{array}{l}\text { Volume } \\
\text { Squared }\end{array}$ & $0.00001 *$ & 0.02502 & 0.00090 & 0.03514 & $0.1326 \theta$ \\
\hline Speed-Volume & $-0.00011^{*}$ & 0.00002 & 0.000001 & -0.00015 & -0.00008 \\
\hline Curve & $0.43220 *$ & 0.09468 & 0.00100 & 0.24760 & $0.6198 \overline{\widehat{\theta}}$ \\
\hline Uphill & 1.96400* & 0.24250 & 0.00622 & 1.50500 & 2.45900 \\
\hline Downhill & $2.85200 *$ & 0.23370 & 0.00625 & 2.41300 & 3.33008 \\
\hline Lanes above2 & $1.25300 *$ & 0.11030 & 0.00120 & 1.03900 & 1.47300 \\
\hline Intercept & $-7.6586 *$ & 0.44410 & 0.01844 & -8.07400 & -6.32900 \\
\hline $\begin{array}{l}\ln \text { (Vehicle } \\
\text { hours per mile) }\end{array}$ & 1 & - & - & - & -10 \\
\hline SL crashes & Mean & SD & MC error & $2.5 \%$ & $\begin{array}{r}97.5 \% \\
11\end{array}$ \\
\hline Speed & $-0.01132 *$ & 0.00374 & 0.00017 & -0.01839 & -0.00413 \\
\hline $\begin{array}{l}\text { Volume } \\
\text { Squared }\end{array}$ & $0.000004^{*}$ & 0.000001 & 0.00000006 & 0.000002 & 0.000003 \\
\hline Speed.Volume & $-0.00003 *$ & 0.00001 & 0.0000004 & -0.00005 & -0.00003 \\
\hline Curve & $0.48210 *$ & 0.04645 & 0.00062 & 0.39050 & 0.57290 \\
\hline Uphill & $2.14900 *$ & 0.10250 & 0.00276 & 1.95500 & $2.356 Q 4$ \\
\hline Downhill & $2.85300^{*}$ & 0.09973 & 0.00275 & 2.66400 & 3.05600 \\
\hline Lanes above2 & $1.21600 *$ & 0.05064 & 0.00078 & 1.11700 & 1.31600 \\
\hline Intercept & $-4.2386 *$ & 0.2322 & 0.01048 & -4.197 & -3.292 \\
\hline $\begin{array}{l}\ln (\text { Vehicle } \\
\text { hours per mile) }\end{array}$ & 1 & - & - & - & $16-$ \\
\hline Dbar & 6588.38 & *significa & t the $95 \%$ & redible inte & 17 \\
\hline$p D$ & 266.504 & & & & \\
\hline DIC & 6854.88 & & & & 18 \\
\hline
\end{tabular}


1 Table 5: Elasticity of speed and the minimum (speed increases by $2.5 \mathrm{mph}$ ) and

2 maximum (speed increases by $5 \mathrm{mph}$ ) expected increase of crashes by type.

\begin{tabular}{|c|c|c|c|c|c|}
\hline \multirow[t]{2}{*}{$\begin{array}{c}\text { Crash } \\
\text { Type }\end{array}$} & \multirow[t]{2}{*}{ Elasticity } & \multicolumn{2}{|c|}{$\begin{array}{c}\text { Percentage of } \\
\text { expected crash } \\
\text { increase } \\
\end{array}$} & \multicolumn{2}{|c|}{$\begin{array}{c}\text { Expected additiona } \\
\text { crashes }\end{array}$} \\
\hline & & Min. & Max. & Min & Max. \\
\hline SV KSI & 2.595 & 10.017 & 20.059 & 19 & 37 \\
\hline SV SL & 1.590 & 6.137 & 12.291 & 54 & $108^{6}$ \\
\hline MV KSI* & 0.886 & 3.420 & 6.849 & 11 & 217 \\
\hline
\end{tabular}

10

11

12

13

14

15

16

17

18

19 


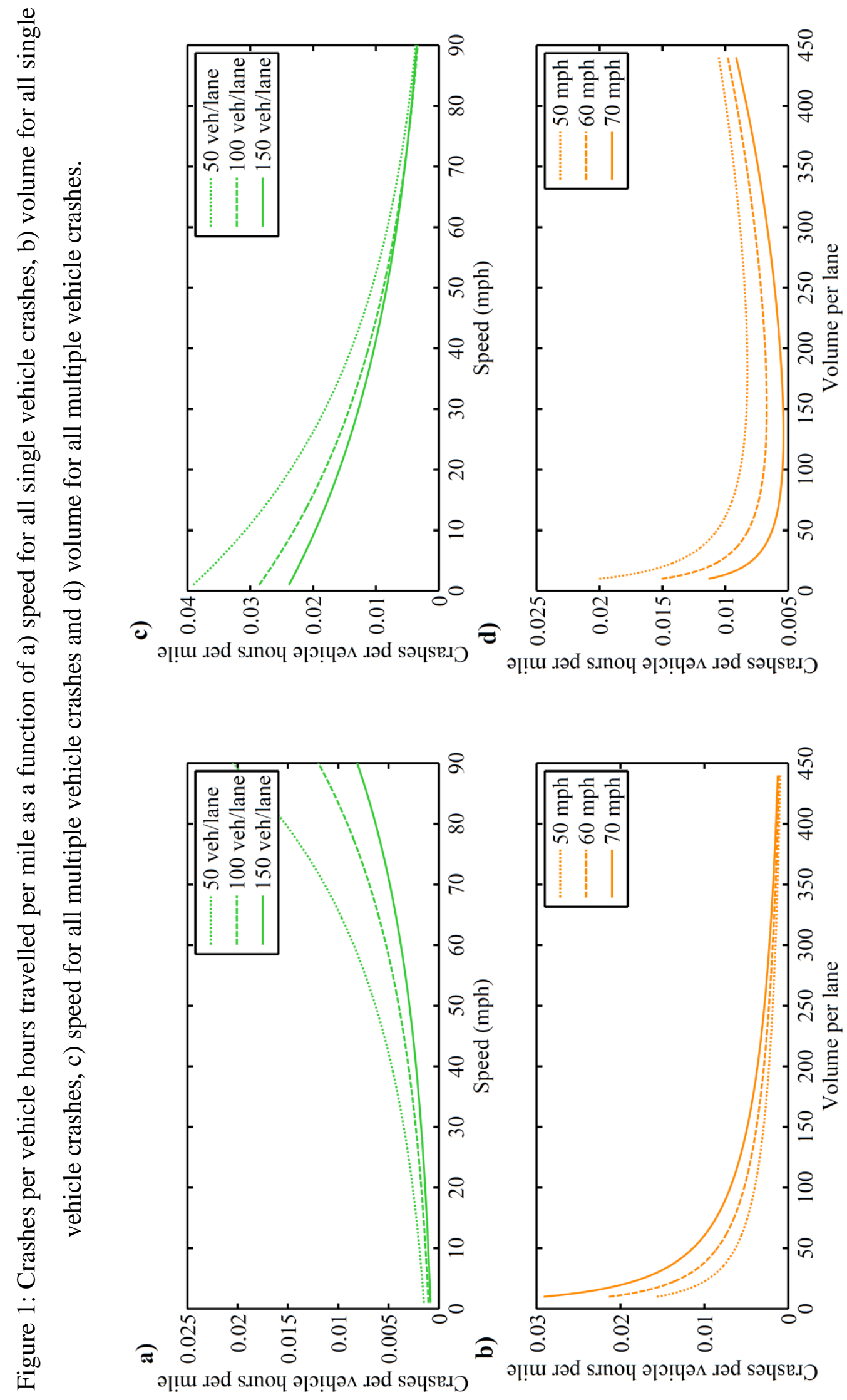


1 Figure 2: 3D contour plot of crash rate for all Single Vehicle crashes as a function of the 2 speed and volume conditions.

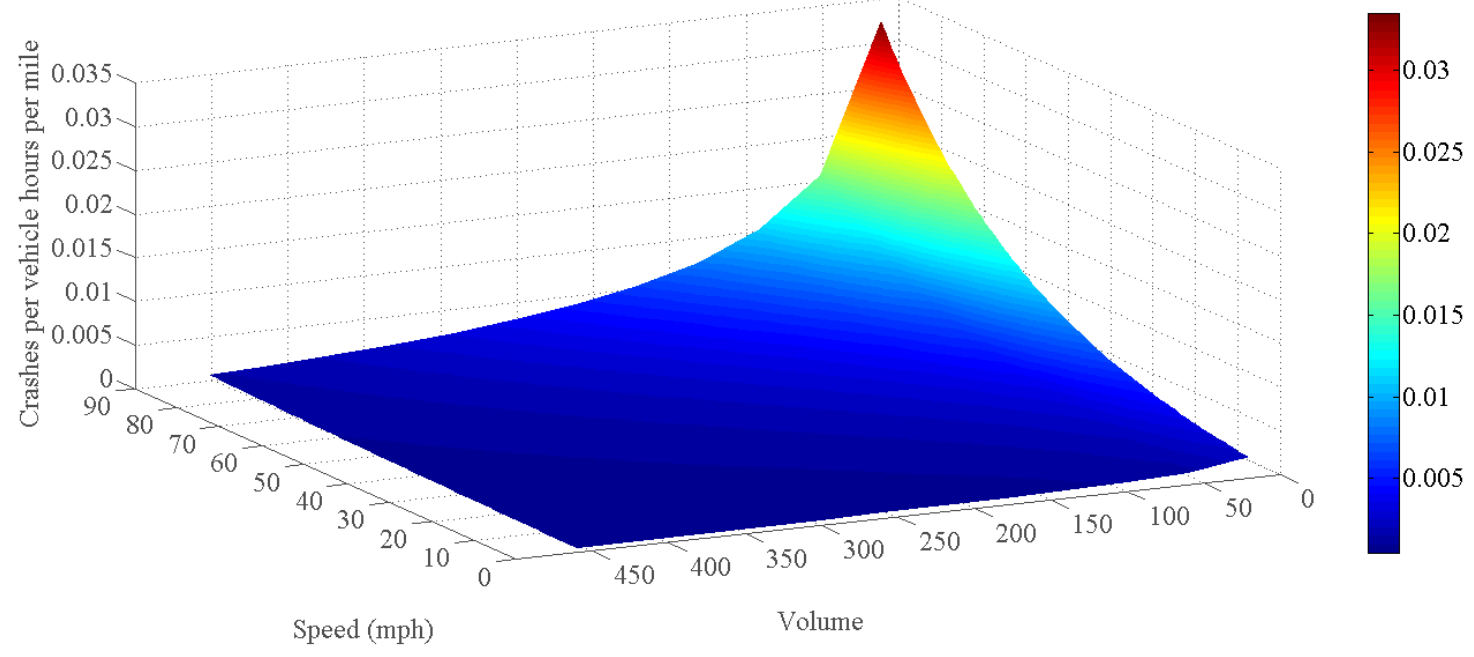

4 Figure 3: 3D contour plot of crash rate for all Multiple Vehicle crashes as a function of 5 the speed and volume conditions.

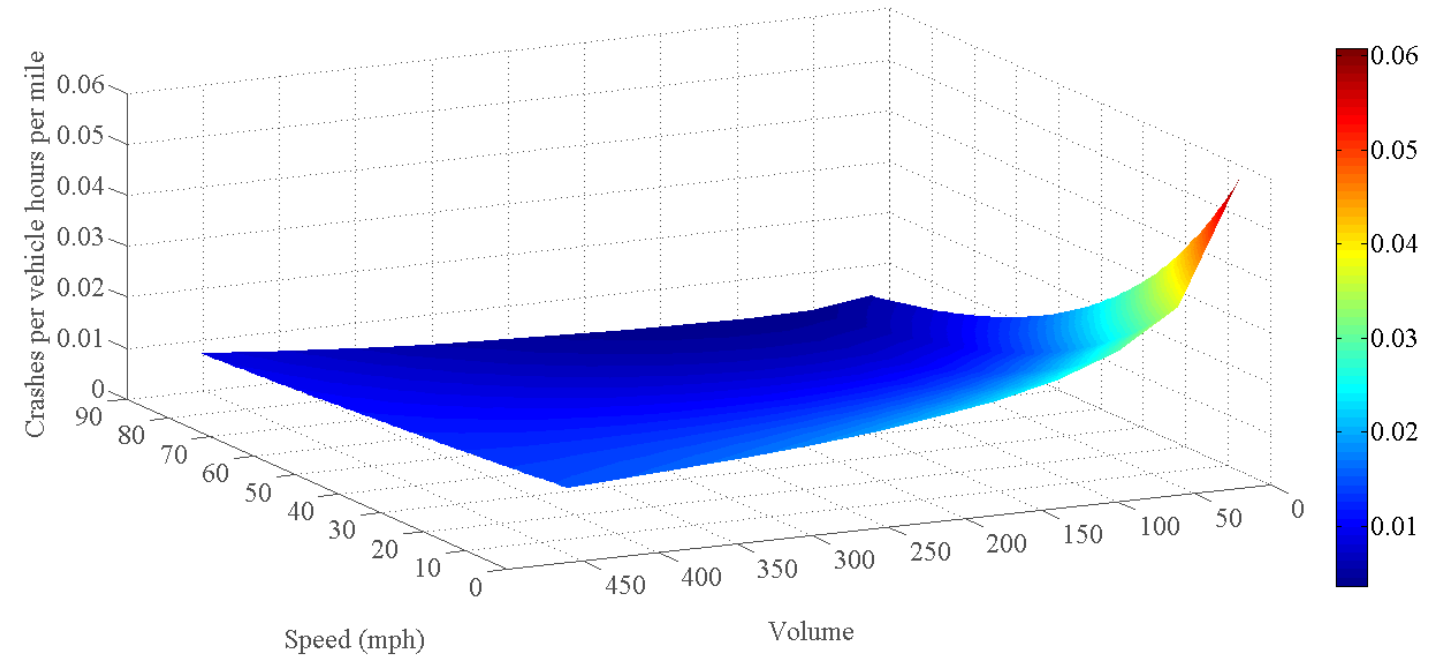




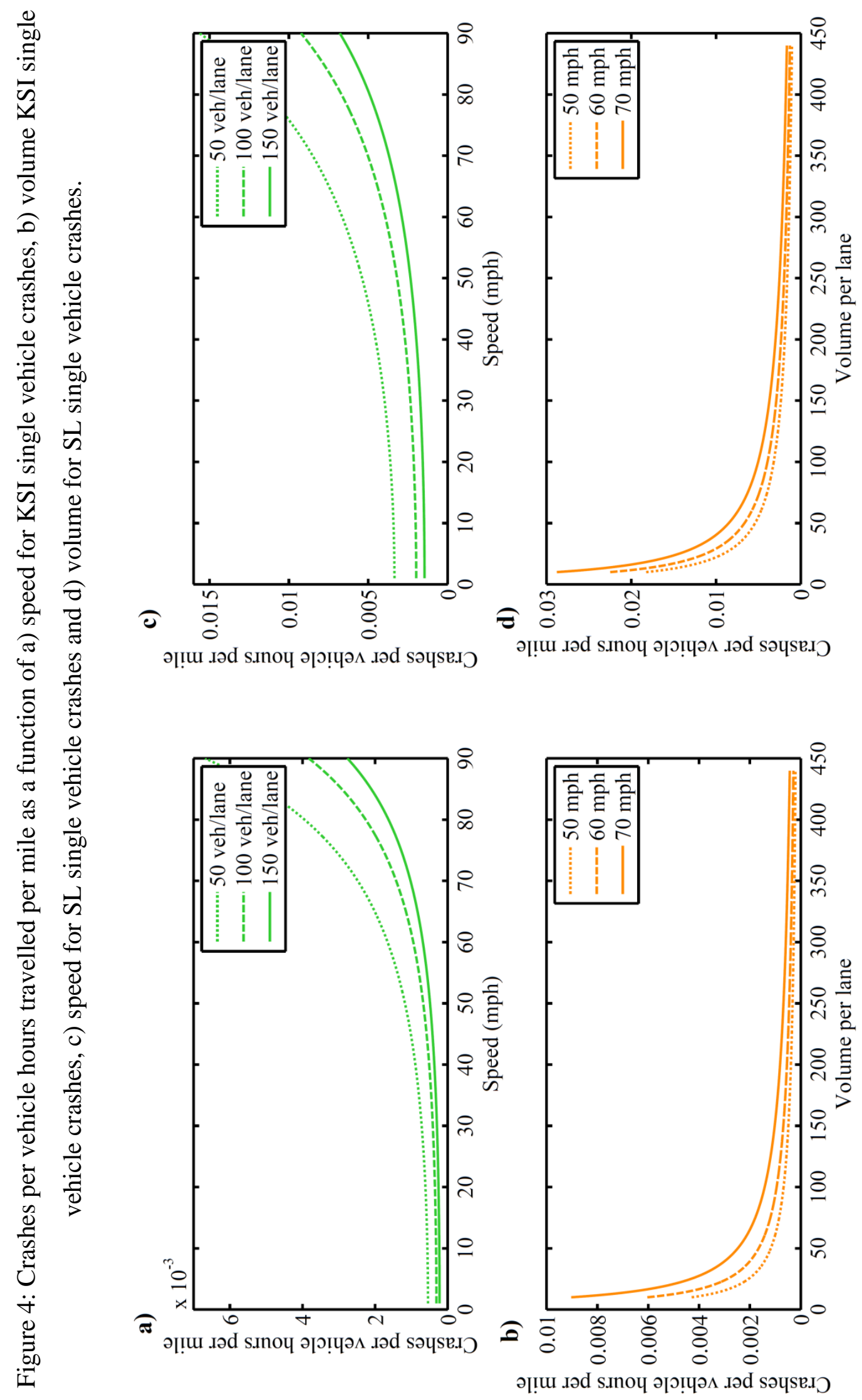


1 Figure 5: 3D contour plot of crash rate for KSI Single Vehicle crashes as a function of 2 the speed and volume conditions.

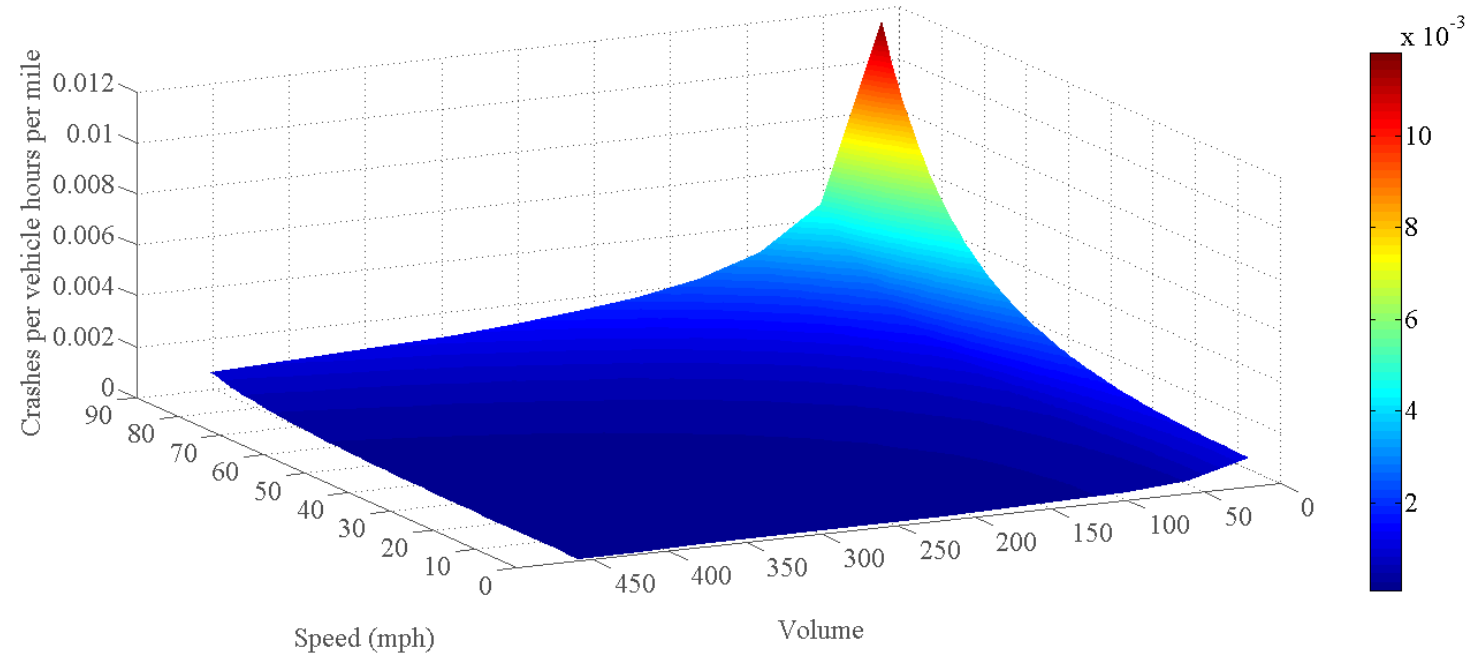

4 Figure 6: 3D contour plot of crash rate for SL Single Vehicle crashes as a function of 5 the speed and volume conditions.

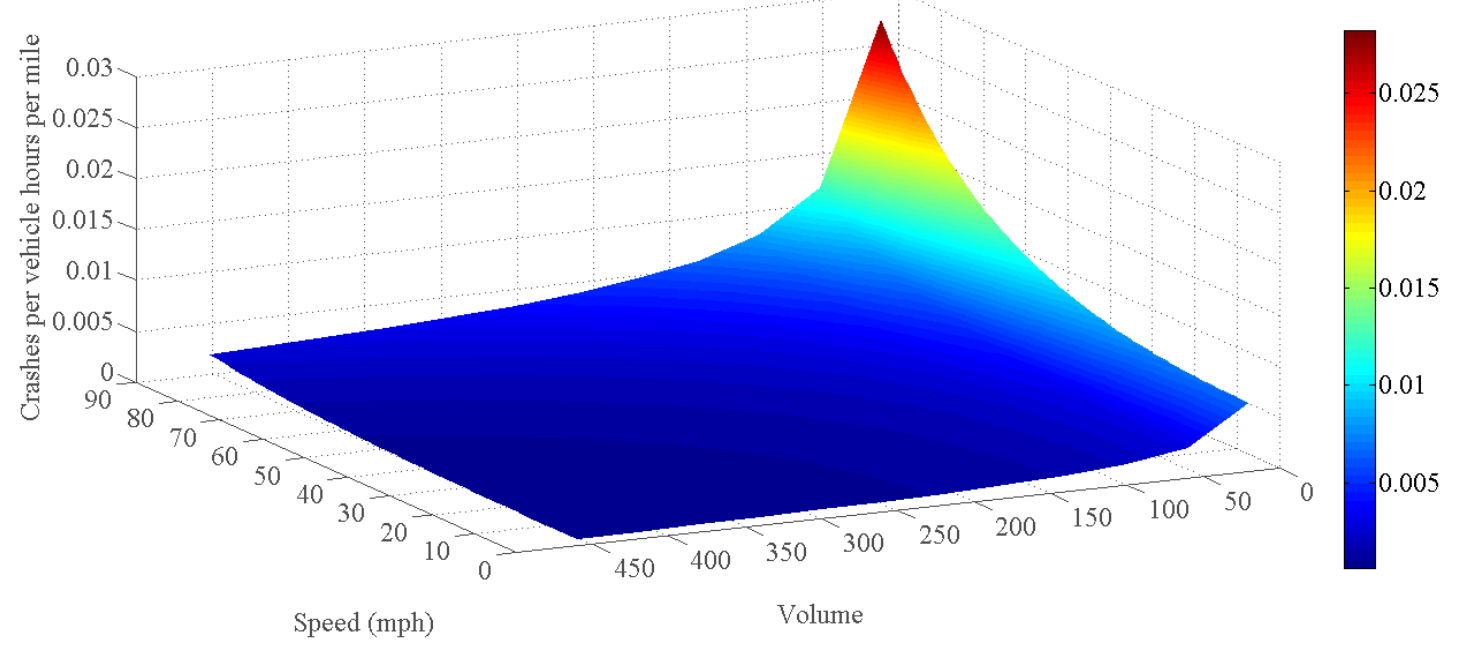




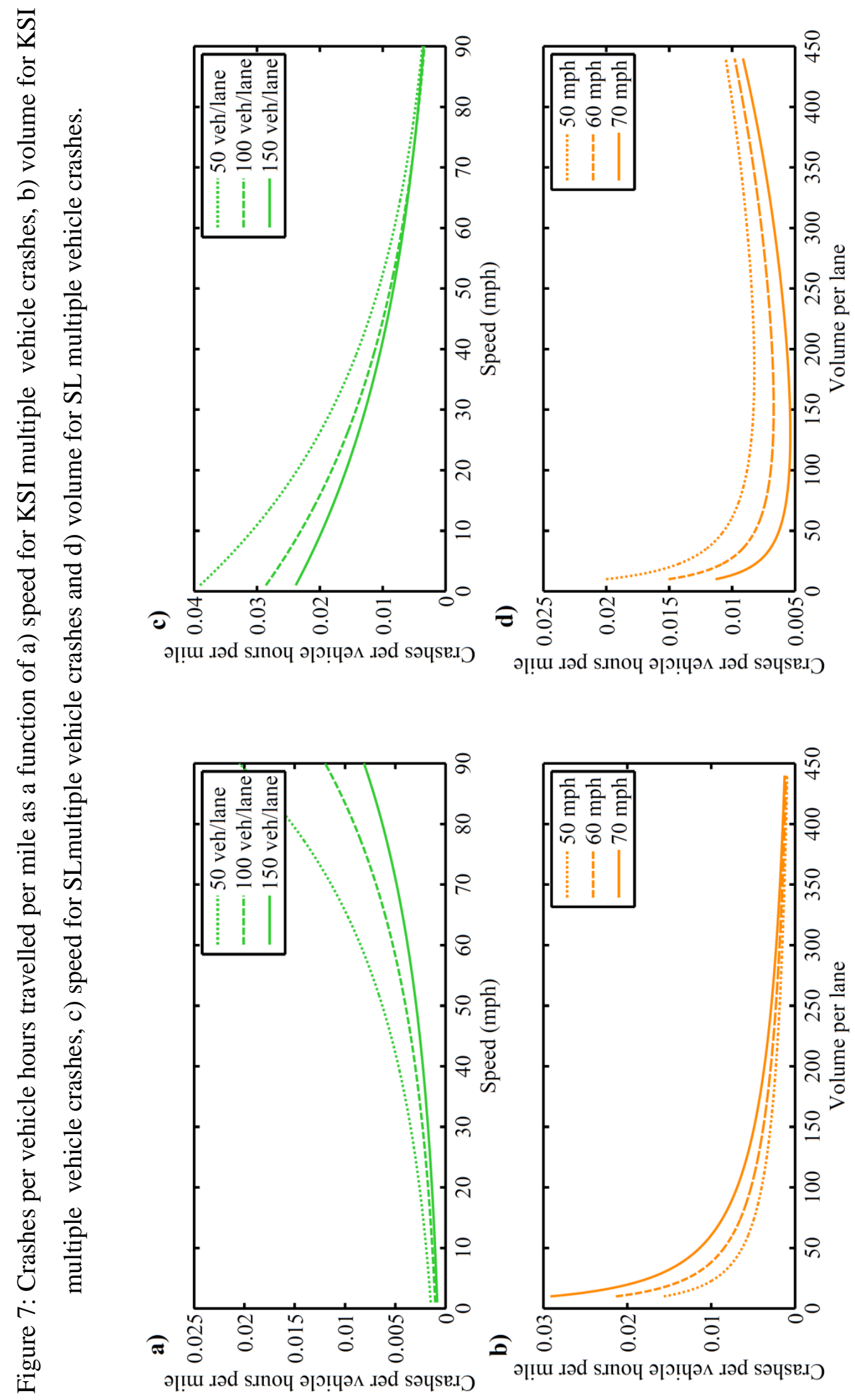


1 Figure 8: 3D contour plot of crash rate for KSI Multiple Vehicle crashes as a function of 2 the speed and volume conditions.

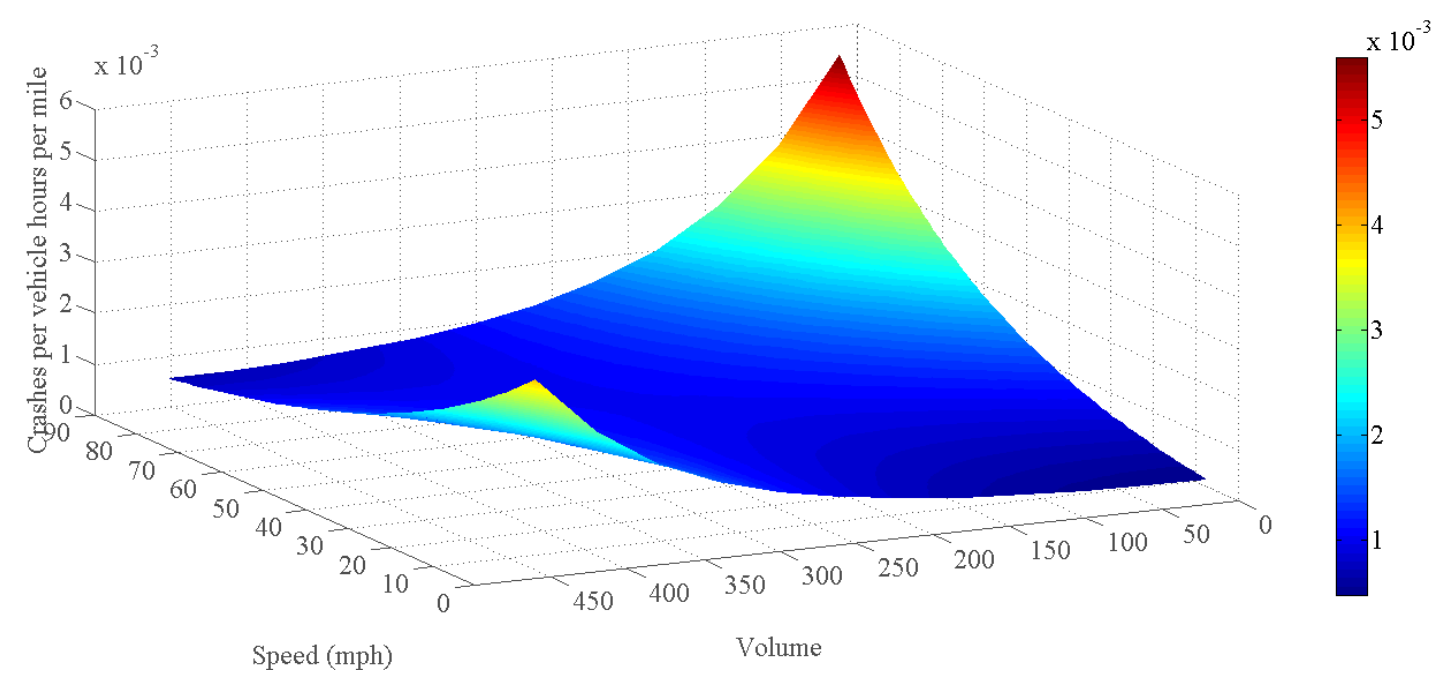

4 Figure 9: 3D contour plot of crash rate for SL Multiple Vehicle crashes as a function of 5 the speed and volume conditions.

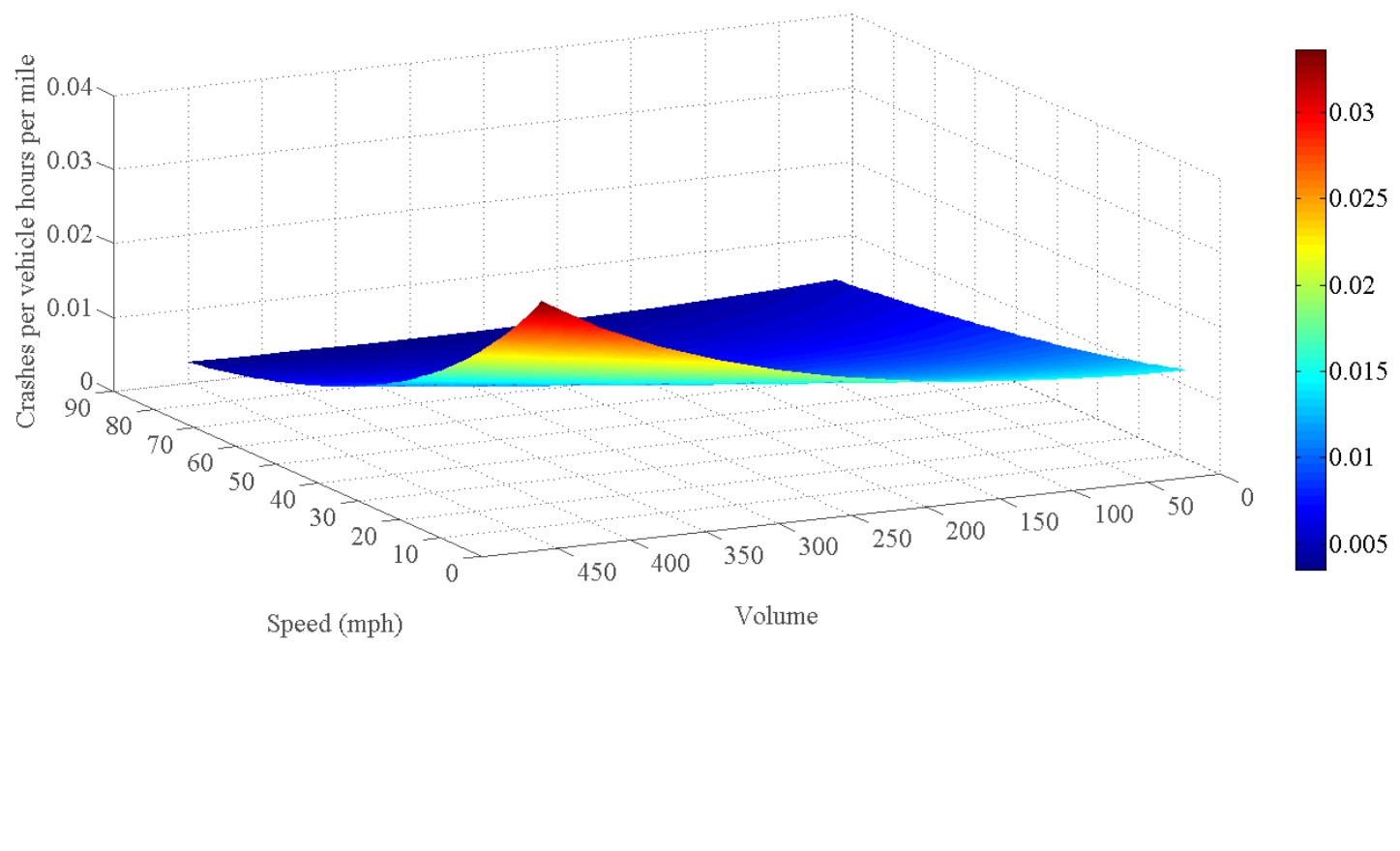

